\title{
EKSPERIMEN MODEL PEMBELAJARAN THINK-PAIR- SHARE DENGAN MODUL(TPS-M) TERHADAP PRESTASI BELAJAR MATEMATIKA DITINJAU DARI MINAT BELAJAR
}

\author{
Jatmiko \\ Prodi Pendidikan Matematika,Universitas Nusantara PGRI Kediri \\ Email: pakjatmiko100@gmail.com
}

\begin{abstract}
Abstrak
Penelitian ini bertujuan untuk mengetahui : (1) manakah diantara Model PembelajaranTPS-M atau Think-Pair-Share" (TPS) yang menghasilkan prestasi yang lebih baik, (2) Manakah yang lebih baik, prestasi belajar matematika siswa yang mempunyai minat belajar tinggi, sedang atau rendah, (3) manakah yang menghasilkan prestasi belajar matematika yang lebih baik, di antara Model Pembelajaran TPS-M dan Think-Pair-Share (TPS) pada siswa yang mempunyai minat belajar tinggi, sedang dan rendah.Penelitian ini menggunakan metode eksperimental semu (Quasi experimental), dengan desain faktorial $2 \times 3$. Populasi penelitian ini adalah semua siswa kelas X SMK kelompok Teknik di Kabupaten Nganjuk Tahun Akademik 2012/2013. Sampel terbagi dalam 2 kelompok, yaitu kelompok eksperimen dan kelompok kontrol. Teknik analisis data yang digunakan dalam penelitian ini, yaitu analisis variansi dua jalan dengan sel tak sama. Berdasarkan hasil analisis diperoleh kesimpulan bahwa: (1) Model pembelajaran TPS-M menghasilkan prestasi belajar matematika yang lebih baik dibandingkan model pembelajaran. (2) Siswa dengan minat belajartinggi, sedang dan rendah memiliki hasil belajar matematika yang sama.(3) Pada masing-masing minat belajar siswa baik tinggi, sedang ataupun rendah prestasi belajar matematika pada model pembelajaran TPS-Mlebih baik dari pada model pembelajaran TPS.
\end{abstract}

Kata Kunci :Think-Pair-Share, Modul, Minat Belajar, Prestasi Belajar Matematika

\section{PENDAHULUAN}

Ilmu merupakan peranan penting

dalam meningkatkan kualitas hidup manusia untuk menjadi hamba yang beriman di hadapan Tuhan Yang Maha Esa, menjadi manusia yang bermanfaat, dan berakhlak mulia.Ilmu merupakan aspek terpenting sehingga dalam segala aspek kehidupan pasti didasari oleh ilmu.
Dalam proses pendidikan di sekolah, kegiatan belajar merupakan kegiatan yang paling pokok. Pendidikan formal yang merupakan salah satu sumber ilmu bagi manusia berkontribusi besar dalam mengembangkan ilmu pengetahuan. Menurut sudjana (2000) dalam Murni dkk (2010), belajar adalah suatu proses yang ditandai dengan 
adanya perubahan pada diri seseorang. Belajar juga dapat dipandang sebagai sebuah proses elaborasi dalam upaya pencarian makna yang dilakukan oleh individu. Proses belajar pada dasarnya dilakukan untuk meningkatkan kemampuan atau kompetensi personal (Pribadi, 2009:6). Hal inilah yang mempengaruhi berhasil tidaknya pendidikan. Dalam pendidikan terjadi interaksi antara guru dengan siswa yang dilakukan dengan cara pembimbingan, pembelajaran dan pelatihan, dengan tujuan mencapai perkembangan siswa secara optimal, menjadikan siswa mandiri (Sugiono, 2010:8).

$\begin{array}{rrrr}\text { Salah } & \text { satu } & \text { cabang } & \text { ilmu } \\ \text { pengetahuan } & \text { yang } & \text { dipelajari } & \text { dalam }\end{array}$ proses pendidikan adalah matematika. Matematika sebagai salah satu ilmu dasar, baik aspek terapannya maupun aspek penalarannya, mempunyai peranan penting dalam pengusaan ilmu pengetahuan dan teknologi, oleh karena itu penguasaan dan pemahaman ilmu matematika dari siswa tingkat sekolah dasar sampai mahasiswa perlu ditingkatkan.

Prestasi belajar matematika sangat dipengaruhi oleh proses pembelajaran matematika di kelas. Pembelajaran yang dilakukan oleh guru pada umumnya masih didominasi oleh pembelajaran langsung di mana susasana kelas cenderung teacher-centered (berpusat pada guru) sehingga siswa menjadi pasif. Menurut teori belajar konstruktivisme, siswa harus membangun sendiri pengetahuan di dalam benaknya berdasarkan pengalaman-pengalaman belajar yang telah mereka miliki, sedangkan guru hanya bertindak sebagai fasilitator yang membantu siswa dalam mengkonstruksi pemahamannya sehingga mampu memecahkan suatu permasalahan dalam pembelajaran. Dalam hal ini, diharapkan terjadinya inovasi pembelajaran oleh guru di dalam kelas. Inovasi pembelajaran tersebut diharapkan mampu memberikan tantangan belajar sesuai kemampuan siswa dengan memperhatikan perbedaan individual siswa,sehingga dibutuhkan suatu model pembelajaran baru yang menuntut siswa agar lebihaktif.

Pembelajaran kooperatif dapat dijadikan sarana bagi guru untuk mengajarkan berbagai keterampilan sosial yang dibutuhkan siswa untuk hidup dan bekerja sama (Arends, 2008). Slavin (2008) mengatakan bahwa metodemetode dalam pembelajaran kooperatif memiliki intervensi sosial, maka seharusnya dapat menghasilkan pengaruh sosial.Dyson dan Rubin (dalam Constantinou, 2010) menyatakan bahwa: "pointed out that cooperative learning 
has many benefits. It can help students to improve motor skills, develop social skills, work together as a team, take control of their learning process, give and receive feedback, and become responsible individuals". Pembelajaran kooperatif memang meningkatkan kontak diantara siswa, memberikan dasar untuk saling berbagi kesamaan, melibatkan dalam kegiatan bersama yang menyenangkan, dan membuat mereka bekerja sama untuk mencapai tujuan bersama. Jelaslah, bahwa semuanya dapat meningkatkan pengaruh positif di antara para siswa.

Menurut Berdine dalam Kennedy (2007), "students place a higher value on learning by participating than on learning by being lectured at and receiving information passively". Salah satu model pembelajaran yang efektif dan mudah diterapkan adalah model pembelajaran Think Pair Shair (TPS). Model pembelajaran kooperatif dengan tipe Think Pair Share (TPS) merupakan salah satu metode pembelajaran yang dirancang untuk mempengaruhi pola interaksi siswa (Trianto 2007). Senada dengan Triyanto, Sutrisno (2007) juga menyatakan bahwa Think Pair Share dapat meningkatkan keaktifan dan kerjasama. Selain itu Azlina (2010) menyatakan, "Think-Pair-Share is a cooperative learning technique which is said as a multi-mode discussion ycle in which studentslisten to a question or presentation, have time tothink individually, talk with each other in pairs, and finally share responses with the larger group".

Selain model pembelajaran penggunaan modul secara efektif dalam pembelajaran matematika dapat meningkatkan pemahaman siswa dalam menerima materi pelajaran matematika yang dapat berimbas pada meningkatnya prestasi belajar siswa.Penggunaaan modul sering dikaitkan dengan aktifitas pembelajaran mandiri (self-intruction). Menambahkan modul pada suatu pembelajaran merupakan model yang bersifat induktif, model ini lebih mengaktifkan siswa dalam belajar mandiri sebelum penamaan konsep atau penyampaian materi dari guru. Sehingga model pembelajaran Think Pair Share (TPS) dengan modul mampu meningkatkan antusiasme siswa dalam proses pembelajaran yang pada akhirnya akan dapat meningkatkan prestasi belajar siswa.

Prestasi belajar siswa yang dicapai dimungkinkan tidak hanya dipengaruhi oleh model pembelajaran yang diterapkan di dalam kelas. Terdapat faktor-faktor lain yang mempengaruhi prestasi belajar matematika yang juga perlu mendapat perhatian dari guru, 
misalnya minat belajar yang dimiliki oleh siswa. Menurut Winkel (1999), minat diartikan sebagai kecenderungan yang menetap, untuk merasa tertarik pada bidang studi atau pokok bahasan tertentu dan merasa senang mempelajari materi itu. Siswa yang berperasaan senang akan mudah berkonsentrasi dalam belajar. Pada dasarnya konsentrasi merupakan akibat dari perhatian yang sifatnya spontan dan ditimbulkan oleh minat terhadap suatu hal. Jika siswa berminat terhadap suatu pelajaran tertentu, maka ia akan berkonsentrasi terhadap pelajaran itu. Siswa tidak akan bosan menekuni sesuatu apabila ia memang berminat terhadapnya.

Berdasarkan latar belakang diatas, dapat dirumuskan masalah sebagai berikut. (1) Manakah diantara Model Pembelajaran TPS-M dan TPSyang menghasilkan prestasi yang lebih baik? (2) Manakah yang lebih baik, prestasi belajar matematika siswa yang mempunyai minat belajartinggi, sedang atau rendah? (3) Manakah yang menghasilkan prestasi belajar matematika yang lebih baik, di antara Model Pembelajaran TPS-M atauThink-PairShare" (TPS) pada masing-masing minat belajar.

\section{METODE PENELITIAN}

Penelitian ini merupakan penelitian eksperimental semu (quasi- experimental research) yaitu peneliti tidak memungkinkan untuk memanipulasi dan atau mengendalikan semua variabel yang relevan dengan rancangan faktorial $2 \times 3$. Menurut Budiyono (2003) tujuan eksperimental semu adalah untuk memperoleh informasi yang merupakan perkiraan bagi informasi yang dapat diperoleh dengan eksperimen yang sebenarnya dalam keadaan yang tidak memungkinkan untuk mengontrol dan atau memanipulasi semua variabel yang relevan.Populasi penelitian ini adalah seluruh siswa kelas X SMK Kelompok Teknik di-Kabupaten Nganjuk tahun pelajaran 2012/2013.Penelitian ini dilaksanakan di SMK Negeri 1 Nganjuk dan SMK Negeri 1 Bagor. Dari masingmasing sekolah diambil dua kelas, kelas pertama mendapat perlakuan model Pembelajaran TPS-M dan kelas kedua yang diberikan model pembelajaran TPS biasa. Variabel bebas dalam penelitian ini adalah model pembelajaran dan minat belajar siswa dengan 3 kategori minat belajartinggi, minat belajarsedang dan minat belajar rendah. Dengan menggunakan analisis variansi satu jalan dengan sel tak sama diperolehpopulasi mempunyai kemampuan awal yang sama.Sedangkan variabel terikat dalam penelitian ini adalah prestasi belajar matematika. Teknik pengumpulan data 
dalam penelitian ini adalah menggunakan (1) metode dokumentasi; (2) metode angket; (3) metode tes. Intrumen penelitian terdiri atas angket minat belajarsiswa dan tes prestasi belajar matematika.

Analisis data dilakukan menggunakan analisis variansi dua jalan dengan sel tak sama. Sebelum analisis dilakukan uji prasyarat analisis variansi yaitu uji Normalitas menggunakan Uji Lilliefors, Uji Homogenitas menggunakan Uji Bartlett. Dari hasil uji diperoleh masing-masing kelompok berdistribusi normal, dan berasal dari populasi yang homogen.

Selengkapnya dapat dilihat pada Tabel 1 dan Tabel 2 dibawah ini:

Tabel1. Hasil Uji Normalitas

\begin{tabular}{|l|l|l|l|l|}
\hline Uji Normalitas & $\mathrm{L}_{\mathrm{Obs}}$ & $\mathrm{L}_{0,05 ; \mathrm{n}}$ & Keputusan & Kesimpulan \\
\hline Kelas TPS-M & 0,075 & 0,107 & $\mathrm{H}_{0}$ Diterima & Normal \\
\hline Kelas TPS & 0,080 & 0,104 & $\mathrm{H}_{0}$ Diterima & Normal \\
\hline Minat BelajarTinggi & 0,092 & 0,147 & $\mathrm{H}_{0}$ Diterima & Normal \\
\hline Minat BelajarSedang & 0,078 & 0,111 & $\mathrm{H}_{0}$ Diterima & Normal \\
\hline Minat BelajarRendah & 0,090 & 0,138 & $\mathrm{H}_{0}$ Diterima & Normal \\
\hline
\end{tabular}

Tabel 2. Hasil Uji Homogenitas

\begin{tabular}{|l|c|l|l|l|}
\hline Sampel & $\chi_{o b s}^{2}$ & $\chi_{0,05 ; n}^{2}$ & Keputusan & Kesimpulan \\
\hline Model Pembelajaran & 0,271 & 3,841 & $\mathrm{H}_{0}$ Diterima & Homogen \\
\hline Minat Belajar & 2,352 & 5,991 & $\mathrm{H}_{0}$ Diterima & Homogen \\
\hline
\end{tabular}

\section{HASIL DAN PEMBAHASAN}

\section{HASIL}

Rerata prestasi belajar matematika pada model pembelajaran TPS-M dan TPS dapat dilihat dalam Tabel 3.

Prosedur uji hipotesis dalam penelitian ini menggunakan Analisis Variansi Dua Jalan dengan sel tak sama. Hasil perhitungan yang telah dilakukan disajikan dalam Tabel 4 berikut:
BerdasarkanTabel4, bahwa untuk model pembelajaran diperoleh $\mathrm{F}_{\mathrm{a}}=4,04>$ $\mathrm{F}_{\text {Tabel }}=3,84$, sehingga $\mathrm{F}_{\mathrm{a}} \in \mathrm{DK}$ dengan demikian hipotesis nol ditolak. Untuk minat belajardiperoleh nilai $\mathrm{F}_{\mathrm{b}}=2,22>$ $\mathrm{F}_{\text {Tabel }}=3,00$, sehingga $\mathrm{F}_{\mathrm{b}} \in \mathrm{DK}$ dengan demikian hipotesis nol ditolak. Untuk interaksi antara model pembelajaran dan minat belajardiperoleh nilai $\mathrm{F}_{\mathrm{ab}}=0,84<$ $\mathrm{F}_{\text {Tabel }}=3,00$, sehingga $\mathrm{F}_{\mathrm{ab}} \notin \mathrm{DK}$ dengan demikian hipotesis nol diterima. 
Berdasarkan hasil tersebut dapat disimpulkan sebagai berikut:

a. Pada efek utama model pembelajaran (A), $\mathrm{H}_{0 \mathrm{~A}}$ ditolak, berarti ada pengaruh model pembelajaran terhadap prestasi belajar siswa. Dengan kata lain, tidak semua model pembelajaran menghasilkan prestasi belajar yang sama. Untuk mengetahui model pembelajaran mana yang lebih efektif dilakukan uji lanjut pasca anava antar b. Pada efek utama minat belajar (B), $\mathrm{H}_{0 \mathrm{~B}}$ diterima, berarti tidak terdapat pengaruh minat belajar yang dimiliki siswa terhadap prestasinya. Jadi tidak perlu dilakukan uji lanjut pasca anava.

c. Pada efek interaksi $(\mathrm{AB}), \mathrm{H}_{0 \mathrm{AB}}$ diterima, berarti tidak terdapat interaksi antara model pembelajaran minat belajaryang dimiliki siswa terhadap prestasinya. Jadi tidak perlu dilakukan uji lanjut pasca anava. baris.

Tabel 3 Rataan Marginal Prestasi Belajar Siswa

\begin{tabular}{|l|l|l|l|l|}
\hline \multirow{2}{*}{ Model Pembelajaran } & \multicolumn{3}{|l|}{ Minat Belajar } & Rataan \\
\cline { 2 - 4 } & Tinggi & Sedang & Rendah & Marginal \\
\hline \hline TPS-M & 84,03 & 78,78 & 71,18 & $\mathbf{7 7 , 7 9}$ \\
\hline TPS & 73,29 & 71,81 & 70,21 & $\mathbf{7 1 , 7 4}$ \\
\hline Rataan Marginal & $\mathbf{7 8 , 9 7}$ & $\mathbf{7 4 , 7 9}$ & $\mathbf{7 0 , 7 3}$ & \\
\hline
\end{tabular}

Tabel 4 Rangkuman Analisis Variansi Dua Jalan Dengan Sel Tak Sama

\begin{tabular}{|l|l|l|l|l|l|l|}
\hline Sumber & JK & $\mathbf{d k}$ & $\mathbf{R K}$ & $\mathbf{F}_{\mathbf{a}}$ & $\mathbf{F}_{\text {Tabel }}$ & Keputusan \\
\hline $\begin{array}{l}\text { Model } \\
\text { Pembelajaran(A) }\end{array}$ & 274,47 & 1 & 274,46 & 4,04 & 3,84 & $\mathrm{H}_{0 \mathrm{~A}}$ Ditolak \\
\hline Minat Belajar(B) & 301,93 & 2 & 150,96 & 2,22 & 3,00 & $\mathrm{H}_{0 \mathrm{~B}}$ Diterima \\
\hline Interaksi ( AB) & 114,67 & 2 & 57,34 & 0,84 & 3,00 & $\mathrm{H}_{0 \mathrm{AB}}$ Diterima \\
\hline Galat & 9103,21 & 134 & 67,93 & - & - & - \\
\hline Total & 9794,28 & 139 & - & - & - & - \\
\hline
\end{tabular}




\section{PEMBAHASAN}

Hipotesis pertama dalam penelitian ini menyatakan bahwa pembelajaran yang menerapkan model pembelajaran TPS-M menghasilkan prestasi yang lebih baik dari pada model pembelajaran Think-Pair-Share" (TPS).Pada efek utama model pembelajaran hanya terdapat dua macam model pembelajaran maka tidak perlu dilakukan uji lanjut. Untuk mengetahui model mana yang lebih efektif maka dilihat rerata marginalnya. Berdasarkan Tabel 3 dapat dilihat bahwa rerata prestasi belajar siswa dengan model pembelajaran TPS-M yaitu 77,79 lebih besar dibanding model pembelajaran TPS saja yaitu 71,74 , sehingga dapat disimpulkan bahwa presatasi belajar siswa dengan model pembelajaran TPS-M lebih baik dibandingkan siswa dengan model pembelajaran TPS. Hal ini disebabkan karena model pembelajaran "Think-PairShare" memiliki beberapa kelebihan, diantaranya adanya interaksi antara siswa melalui diskusi untuk menyelesaikan masalah yang akan meningkatkan keterampilan siswa dan juga baik siswa yang pandai maupun siswa yang kurang pandai sama-sama memperoleh manfaat. Apalagi ditambah dengan modul, dimana siswa dapat lebih banyak melakukan latihan soal serta pengembangan soal ataupun pengembangan materi dari modul.

Hipotesis kedua dalam penelitian ini menyatakan bahwa siswa dengan minat belajar tinggi memiliki prestasi lebih baik dari siswa yang mempunyai minat belajarsedang dan rendah. Selain itu siswa yang mempunyai minat belajar sedang memiliki prestasi lebih baik dari pada siswa yang mempunyai minat belajarrendah.Pada efek utama minat belajar(B), $\mathrm{H}_{0 \mathrm{~B}}$ diterima, berarti tidak terdapat pengaruh minat belajaryang dimiliki siswa terhadapprestasinya. Dengan kata lain, siswa dengan minat belajartinggi, minat belajarsedang, dan minat belajarrendah memiliki prestasi belajar matematika yang sama. Ada kemungkinan hal ini disebabkan pada pokok bahasan yang dipelajari, sehingga dalam penerapan model-model pembelajaran ini cenderung sama, juga pada proses pembelajaran guru kurang maksimal dalam menerapkan masingmasing model dikarenakan guru kurang memahami proses pembelajaran yang ada dalam RPP.Hal ini juga sama dengan penelitian yang pernah dilakukan oleh Dewi (2012) yang menyimpulkan tidak terdapat pengaruh antara minat belajar tinggi, sedang, dan rendah terhadap hasil belajar siswa.

Hipotesis ketiga dalam penelitian ini menyatakan bahwa pada masing- 
masing tingkat minat belajar, model pembelajaran TPS-M menghasilkan prestasi belajar matematika lebih baik dari pada model pembelajaran ThinkPair-Share” (TPS). Berdasarkan perhitungan anava dua jalan dengan sel tak sama diperoleh $\mathrm{H}_{0 \mathrm{AB}}$ diterima, berarti tidak terdapat interaksi antara model pembelajaran dan minat belajarterhadap prestasi belajar matematika siswa. Karena tidak terdapat interaksi antara model pembelajaran yang digunakan dan minat belajar, maka untuk mengetahui keefektifan model pembelajaran pada masing-masing tingkat minat belajarmengacu kepada hipotesis sebelumnya.

Dalam hasil uji hipotesis pertama sudah dijelaskan bahwa model Pembelajaran TPS-M mempunyai prestasi belajar yang lebih baik dibandingkan siswa dengan model Pembelajaran TPS. Dari hasil uji hipotesis tersebut dapat dijelaskan bahwa pada model pembelajaran TPS-M memiliki prestasi yang lebih baik dari model pembelajaran TPS sehingga pada masing-masing tingkat minat belajar(tinggi, sedang dan rendah) model pembelajaran TPS-M mempunyai prestasi belajar yang lebih baik dari pada siswa dengan model pembelajaran TPS. Hasil penelitian ini menunjukkan bahwa masing-masing minat belajarsiswa baik tinggi, sedang ataupun rendah prestasi belajar matematika pada model pembelajaran TPS-Mlebih baik dari pada model pembelajaran TPS.

\section{KESIMPULAN DAN SARAN}

Berdasarkan hasil analisis data yang telah dilakukan, maka dapat disimpulkan sebagai berikut. (1) Model pembelajaran TPS-M memberikan prestasi belajar matematika yang lebih baik dibandingkan model pembelajaran TPS.(2) Siswa dengan minat belajartinggi, sedang dan rendah memiliki hasil belajar matematika yang sama.(3) Pada masing-masing minat belajarsiswa baik tinggi, sedang ataupun rendah prestasi belajar matematika pada model pembelajaran TPS-Mlebih baik dari pada model pembelajaran TPS.

Berdasarkan hasil penelitian dan pembahasan di atas, maka penulis menyarankanguru hendaknya:(a) dalam pelajaran matematikasebaiknya memilih model pembelajaran yang tepat sehingga pembelajaran dapat berlangsung lebih efektif;salah satunya dengan model pembelajaran TPS atau dengan TPS yang di modifikasi dengan Modul,(b) senantiasa memperhatikan minat belajarsiswa pada pembelajaran matematika;jika guru menjumpai siswa dengan minat belajarrendah hendaknya dapat memberi perhatian yang lebih, 
sehingga siswa merasa nyaman dalam menerima pelajaran matematika,

Sedangkan untuk siswa hendaknya:(a)dalam mengikuti pembelajaran kooperatif, turut terlibat secara aktif dalam melakukan diskusi kelompok agar mampu mengkonstruksi pemahaman suatu konsep yang sedang dipelajari, bersedia memperhatikan dan menghargai penjelasan, pendapat, pertanyaan atau jawaban dari anggota kelompok lain,(b) tidak perlu malu untuk bertanya atau berkonsultasi kepada guru jika masih belum paham akan materi yang telah didiskusikan dengan kelompok, agar dalam pertemuan selanjutnya siap menerima materi selanjutnya.

\section{DAFTAR PUSTAKA}

Arends.I.R. 2008.Learning To Teach. Terjemahan: Helly Prajitno Soetjipto.Yogyakarta: Pustaka Pelajar

Azlina, N. A. N. 2010. "CETLs • Supporting Collaborative Activities Among Students and Teachers Through the Use of Think- Pair-Share Techniques”. International Journal of Computer Science Issues, Volume 17, Issue 5, Di unduh dari: http://ijcsi.org/papers/7-5-18- 29.pdf. Pada tanggal 28 Februari 2013 pukul 21.00 WIB.

Budiyono, 2003.Metodologi Penelitian Pendidikan. Surakarta: UNS Press.

Dewi, A. N. 2012. Pengaruh Penggunaan Model Active Knowledge Sharing Terhadap Hasil Belajar Ditinjau Dari Minat Belajar Siswa SMA N 2 Karanganyar. Jurnal Pendidikan Biologi. Diunduh dari http://jurnal.fkip.uns.ac.id/index. php/bio/article/d ownload/37/25.Pada tanggal 28 maret 2013 pukul 19.50 WIB.

Constantinou, P. 2010. Keeping the Excitement Alive: Tchoukball and Cooperative Learning.Journal of Physical Education, Recreation \& Dance.Vol. 81, Iss. 3; p. 30-35.

Handayani, S.S. 2010. Ekperimentasi Pembelajaran Matematika dengan Menggunakan Model Struktural Think Pair Share (TPS) Pada Materi Pokok Bentuk Akar dan Pangkat Ditinjau dari Gaya Belajar Matematika Siswa. Tesis. UNS

Kennedy, R. 2007. In-Class Debates: Fertile Ground for Active Learning 
and the Cultivation of Critical Thinking and Oral Communication Skills. International Journal of Teaching and Learning in Higher Education, Volume 19, Number 2, PP 183-190. Di unduh dari : http://www.isetl.org/ijtlhe/pdf/ijtlh e200.pdf. Pada tanggal 28 maret 2013 pukul 19.50 WIB.

Murni, atma, nurul yusra $\mathrm{T}$, titi solfitri. 2010. Penerapan model pembelajaran aktif tipe Group to group exchange (GGE) untuk meningkatkan hasil belajar matematika siswa kelas X IPS 1 Man 2 model pekan baru. Jurnal penelitian pendidikan vol. 11 No. 2. PP 1-12

Pribadi, Benny A. 2011. Model Desain Sistem Pembelajaran. Jakarta: dian Rakyat.

Slameto, 2003.Belajar dan Faktor-faktor yang Mempengaruhinya. Jakarta: Rineka Cipta.

Sugiono. 2010. Belajar dan Pembelajaran. Kediri: Universitas Nusantara PGRI.

Sutrisno. 2007. "Penerapan Pembelajaran Kooperatif Tipe Think-Pair-Share terhadap Hasil Belajar
Matematika". Jurnal Pendidikan. 4(4). 37-43.

Trianto. 2007. Model-Model pembelajaran Inovatif Berorientasi Konstruktivistik. Jakarta : Prestasi Pustaka

Winkel, W. S. 1999. Psikologi Pengajaran Edisi Revisi. Gramedia Widiasarana Indonesia. Jakarta 